\title{
A SEGURANÇA SANITÁRIA NUM MUNDO GLOBAL: OS ASPECTOS LEGAIS. O SISTEMA DE SEgURANÇA SANITÁRIA NA FranÇA
}

SANITARY SECURITY IN A GLOBALIZED WORLD: LEGAL FEATURES. SANITARY SYSTEM IN FRANCE

Christelle Durand ${ }^{* \prime}$

\section{RESUMO}

O tema da saúde pública está ligado hoje ao da reorganização administrativa e da atualização institucional. Na França esse questionamento é patente, dadas as crises sanitárias verificadas, as quais desencadearam, ao longo da história, a reforma da saúde pública. Dessa forma, o novo campo de ação da segurança sanitária se resume em duas preocupações: uma reforma institucional e sua expansão aos domínios alimentares e ambientais. Estas preocupações, por sua vez, têm sido alvo de interesse do legislador.

As decisões em saúde pública são moldadas por elementos de uma crise sanitária: a urgência, um elemento catalisador que leva a criações institucionais; a reincidência, que provoca uma análise de suas causas e do sistema; a percepção dos riscos pelo público, ligada às políticas de gestão de riscos.

A visão da saúde pública, como um sistema fragmentado, é transformada pela noção de segurança sanitária como função essencial do governo. $O$ direito, portanto, progride estimulado pelas crises, visando a um sistema coerente de preservação da saúde, cujos princípios se fundam na separação das funções e na precaução. Nesse sentido, a resposta do sistema francês a essa evolução levou ao surgimento das agências, distintas do Estado e sob tutela ministerial, e à criação da Lei n. 98-535, de $1^{\circ}$ de julho de 1998 , que regulamentou novas instituições de gestão por setores e iluminou a conveniência de uma política com outros Estados.

\section{Palavras-chave}

Segurança Sanitária, Crises Sanitárias, Evolução, Instituições.

(*) Professora Doutora na Faculté de Droit et des Sciences politiques de Nantes (France) e Pesquisadora no Centre de Recherche en Urbanisme Aménagement Régional et Administration Publique. 


\begin{abstract}
Public health is a theme wich is linked to administrative reorganization and institutional actualization, in France nowadays. The decisions in public health are shaped by elements from sanitary crisis: emergency, reicindency, peoples risk evaluation. The public health fragmented system is transformed by the idea of health security as an essential government function. Thus, there is a positive evolution caused by crisis, aiming at coherent health system, wich principles are based on the separation of the function and on precaution. This evolution of the French system led to the agencies and to the creation of the French Health Security System by the law n. 98.535.
\end{abstract}

\title{
Key words
}

Health Security, Public Health, Agencies, Health Law.

\section{INTRODUÇÃO}

Desde os anos 70, a demanda crescente contra os riscos de toda espécie ao Estado tem sido a conseqüência direta das crises que eram assunto principal do jornalismo, mas também de uma nova sensibilidade da população às questões do meio ambiente e sanitárias. A saúde pública, "conjunto das ações que visam a melhorar a saúde da coletividade, não visando diretamente a um indivíduo"(1), é hoje o assunto principal de uma polêmica que precisa de uma reorganização administrativa.

O sistema francês de segurança sanitária tem sido objeto, na última década, de reavaliação e atualização institucional em resposta a uma acusação de "derrota da saúde pública"(2). Segundo Aquilino Morelle, essa "derrota era no mínimo inevitável: num contexto de generalização dos riscos difusos e incertos, a carência das instituições, que têm a responsabilidade pela saúde das populações associadas às falhas humanas ${ }^{(3)}$ e acrescidas pela renovação da responsabilidade devida à tradução jurídica do princípio da precaução, leva inevitavelmente a crises sanitárias".

Uma crise sanitária pode se definir como uma ameaça, real ou suposta, para o estado de saúde do povo, conjugada à desestabilização dos poderes públicos responsáveis pela segurança sanitária, e dirigida pela mídia. Todos os escândalos que marcaram os anos 80 e 90 - Chernobil, transmissão da AIDS por transfusão, hormônios de crescimento, vaca louca, amianto, excesso de leucemias na proximidade de Hague $\left.{ }^{\circ}\right)$, frangos com dioxina... - não correspondem à definição da crise: de fato, alguns

(1) Bernard Cassou e Michel Schiff. Qui décide de notre santé? Le citoyen face aux experts. Paris: Syros, 1998 , p. 7

(2) Aquilino Morelle. La défaite de la santé publique. Paris: Flamarion, 1996, 389 p. Ver também o relatório entregue ao Secretário de Saúde do Estado sobre o ministério da saúde dirigido pelo Primeiro Ministro Alain Juppé em 1996 (relatório entregue em janeiro de 1997).

(3) Condenação do Estado francês por "falta culposa na questão do sangue contaminado".

(") Cidade do norte da França que abriga uma central de tratamento de dejetos nucleares. 
casos não foram divulgados pela mídia (hepatite $C$ ) ou não tiveram como conseqüência a desestabilização do sistema de segurança sanitária (a questão de Hague).

Como as crises sanitárias têm se repetido, o sistema é sempre questionado. Entretanto a saúde pública tem evoluído. Assim, o Ministério da Saúde nasceu em 1920 como conseqüência direta da epidemia da gripe espanhola que causou de 160.000 a 240.000 mortes. As diferentes crises devido ao uso de medicamentos ou de produtos cosméticos (a questão do pó Baumol em 1952, Stalinon em 1954, efeitos da talidomida em 1960, talco Morhange en $1973^{(4)}$ ) foram, cada uma, a oportunidade de reforma do sistema sanitário.

A referência à segurança faz imediatamente surgir o papel de quem decidirá, e portanto do Estado, na gestão dos riscos sanitários. A expressão segurança sanitária, que foi usada oficialmente pela primeira vez em 16 de setembro de 1992, nos debates parlamentares relativos ao projeto de reforma da transfusão de sangue, foi mais tarde definida como "a segurança das pessoas contra os riscos terapêuticos de toda espécie, riscos ligados tanto à escolha terapêutica, aos atos de prevenção, de diagnóstico ou de tratamentos, ao uso de bens e produtos de saúde, quanto às intervenções e decisões das autoridades sanitárias"(5). Essa definição limitada aos riscos iatrogêni$\cos ^{(6)}$, dada por $M$. Tabuteau, é hoje insuficiente para conter toda a questão(7), uma vez que se viu, com a questão da vaca louca, com o excesso de leucemias em torno de Hague ou então com o frango com dioxina, que a segurança sanitária não se restringe apenas ao campo da prática médica. Ela encampa hoje a alimentação ${ }^{(8)}$ e o meio ambiente ${ }^{(9)}$.

Os escândalos do sangue contaminado e do hormônio de crescimento (ambos produziram efeitos tardios a partir de 1992) são o verdadeiro arquetipo do novo campo de ação da segurança sanitária:

- o início imediato de uma reforma institucional em resposta direta à uma situação de crise (l);

- a necessidade de ampliar o campo da segurança sanitária aos domínios alimentares e ambientais ${ }^{(10)}$ (II).

(4) Para uma idéia desses casos, cf. Françoise Lalande, "Segurança e vigilância sanitária: conceitos, histórico, evoluçāo das estruturas e das doutrinas", in La sécurité sanitaire: enjeux et questions. RFAS ns. 3-4, 1997, pp. 31 e ss.

(5) D. Tabuteau, La sécurité sanitaire, Berger-Levreau, 1994, p. 11.

(6) Risco desencadeado pelo tratamento médico e mais amplamente pelo sistema de saúde.

(7) Pierre-Yves Verkindt, que menciona esse autor, acha que essa definição é "bastante restrita". In Pierre-Yves Verkindt, Sécurité sociale et sécurité sanitaire: bref retour sur la loi du ler juillet 1998 relative au renfoncement de la veille sanitaire, $\mathrm{RD}$ sanit. Soc., 35(1), janv-mars 1999, p. 39.

(8) Criação pela lei de 1998 da Agência de Segurança Sanitária dos Alimentos.

(9) Ver nesse sentido: Odette Grzegrzulka e André Aschieri, Propositions pour le renforcement de la sécurité sanitaire environnementale. Relatório a Primeiro Ministro, Paris, 16 de novembro de 1998; Proposta de lei relativa ao reforço da segurança sanitária e meio ambiente e vigilância de meio ambiente, Assembléia Nacional.

(10) A seguir, a crise da vaca louca estendeu-se geograficamente no campo da segurança sanitária, uma vez que uma das particularidades desta questão é que seja instaurada uma mudança de escala, pois a crise tomou conta do espaço europeu. 
Estas duas preocupações caracterizam a reforma do processo de decisão no domínio da saúde pública e são acompanhadas de um aumento de interesse do legislador: as recentes grandes reformas propostas são impulsionadas pelo Parlamento (e particularmente pelo Senado), o que hoje é bem raro para ser destacado. Tanto a criação das agências - Agência Francesa do Sangue, Agence Française du Sang (AFS), e Agência dos Medicamentos, Agence du Médicament (AM), em 1993 - quanto as propostas de reforço da vigilância sanitária(11), ou aquelas da segurança sanitária ambiental $^{(12)}$, são de origem parlamentar. O projeto de lei relativo à transparência em questāo nuclear, à segurança nuclear e à proteção contra os raios ionizantes tem origem no relatório do Gabinete Parlamentar de Avaliação das Escolhas Científicas e Tecnológicas (13), Office Parlementairaire d'Évaluation des choix Scientifiques et Technologiques (OPECST). Esse projeto de lei prevê a criação de uma Autoridade de segurança nuclear e de radioproteção. Ele é, principalmente, o testemunho do esforço dispendido pelos poderes públicos para favorecer as inciativas parlamentares nas questões de saúde/meio ambiente.

\section{A REFORMA DA SAÚDE PÚBLICA DESENCADEADA PELAS CRISES ${ }^{(14)}$}

Na França, a evolução da intervenção dos poderes públicos no domínio da saúde pública pode ser reagrupada em três etapas essenciais:

- A partir da segunda metade do século XVIII, uma política chamada "higienista" permitiu que se colocasse em prática um sistema de saúde pública(15) com o objetivo de evitar o risco "natural", ou seja, o risco de doença ou acidente ${ }^{(16)}$.

- No começo do século $X X$, os progressos da medicina e a diminuição das grandes patologias trazem uma mudança radical: o sistema é organizado de acordo com uma lógica da eficáca de tratamentos e, in fine, de melhorar o estado de saúde da população.

(11) Relatório elaborado pela missão de informação da Comissão dos Assuntos Sociais da Assembléia Nacional (relatório n. 196, Assembléia Nacional, 1997).

(12) Odette Grzegrzulka e André Aschieri, cit., e Proposta de lei relativa ao reforço da segurança sanitária e meio ambiente e vigilância do meio ambiente, Assembléia Nacional, cit.

(13) Claude Birraux, Rapport sur le contrôle de sureté et de la sécurité des installations nucléaires - Deuxième partie: Le bilan et les perspectives de la politique de sûreté des installations nucléaires. Assembléia Naciona! n. 1.496 - Senado n. 285. Esse relatório pode ser consultado pela Internet, nos sites da Assembléia Nacional (http://www.assemblee-nationale.fr) e do senado ( $h$ ttp:// www.senat.fr).

(14) Cf. Senador Huriet, “ $L$ histoire nous enseigne très souvent que la législation progresse réellement à la faveur des crises", cit.

(15) Se a responsabilidade torna-se coletiva diante das epidemias, como a da peste em Mareseille no século XVIII e da cólera em 1849, o Estado não deve impor regras sanitárias nos lugares pri-vados. (16) Cf. Didier Tabuteau. La sécurité sanitaire. Berger Levrault, 1994. Do mesmo autor, Les pouvoirs publics ef le risque sanitaire. RFAS n. 2-1996, pp. 29 e ss. Ver também François Lalande, Sécurité et veille sanitaire: concepts, historique, évolution des stuctures et des doctrines. RFAS ns. 3-4, dezembro 1997, pp. 31 e ss. 
- Enfim, as descobertas dos riscos jatrogênicos e os escândalos que marcaram a atualidade das duas últimas décadas mudaram as opiniões, e, também, as instituições que se revelaram incapazes de gerir os riscos. A segurança sanitária foi repensada e a gestão administrativa reorganizada.

O aparecimento de uma crise na cena pública, muito aumentada desde a era da mida, põe em destaque as fraquezas e lacunas do sistema. Uma mudança institucional intervém tardiamente para remediar um problema atual. É, portanto, a crise que pressupõe a ação no domínio da saúde pública $(A)$.

A questão do sangue contaminado provocou, contudo, uma verdadeira reviravolta na saúde pública. A melhora da gestão da saúde pública deve progredir, pois a opinião pública estima que o responsável último pelo sistema é o Estado(17). A noção de segurança sanitária então aparece. Ela permite recolocar o sistema, julgado fragmentário e falido, em meio às missões essenciais do Estado (B).

\section{A - A Urgência como Catalisadora das Decisões em Saúde Pública}

\section{Uma gestão a posteriori da crise}

No sistema de segurança sanitária, a resposta institucional vem a posteriori, quando o fenômeno da crise começou ou terminou, deixando pouco espaço para uma lógica coerente de prevenção.

Primeira resposta imediata a uma crise descrita pela doutrina, o Decreto Real, de 3 de março de 1822, institui as defesas sanitárias nas fronteiras contra epidemias como a pesta, o cólera ou a febre amarela. O Decreto foi votado quando esta última epidemia assolou a península ibérica. A lei de 15 de fevereiro de $1902^{(18)}$, sobre a proteção da saúde pública, seguiu-se à epidemia do cólera que causou grandes estragos em Toulon em 1884. E é bom lembrar que o ministério de higiene, anterior ao mistério da saúde, foi criado em 1920, logo após a epidemia de gripe espanhola que causou um número significativo de mortes em 1918 e 1919.

Durante os últimos trinta anos, a vigilância dos riscos ligada aos bens médicos (medicamentos, produtos sagüíneos, lábeis dispositivos médicos...) se desenvolve também ao sabor das crises. Assim a vigilância de medicamentos foi criada pela OMS logo a seguir da questão da talidomida. Igualmente, a criação da hemovigilância resultou do escândalo do sangue contaminado e a vigilância dos materiais surgiu, na Europa, logo após os problemas causados por determinadas sondas cardiacas e próteses mamárias.

Ainda hoje, o processo de decisão permanece em um mecanismo de resposta urgente em caso de crise. No início dos anos 90 , a questão do

(17) Através do questionamento dos ministros.

(18) Declarada nula em 1982. 
sangue contaminado resultou na criação da Agência Francesa do Sangue e acelerou a criação da Agência francesa dos Medicamentos. O Secretário de Estado da Saúde criou, em 1992, a Rede Nacional de Saúde Pública, Réseau National de Santé Publique (RNSP), e o Estabelecimento Francês de Transplantes, Etablissement Français de Greffes (EFG), foi criado em 1994, logo após a crise de retirada de órgãos.

No que diz respeito à crise da vaca louca, ela está na origem da reforma do sistema empreendida neste fim de século pela Lei de $1^{\circ}$ de julho de $1998^{(19)}$. Assim, segundo o senador Huriet, "é necessário hoje aproveitar a ocasião provocada pela crise chamada de encefalopatia espongiforme bovina (ESB), e utilizar as constatações de carência do poder público divulgadas pela imprensa, o relatório do nosso excelente colega o deputado Jean-François Mattéi e o relatório preparado pelo Parlamento europeu para melhorar a segurança sanitária dos produtos alimentares".

Assim sendo, a urgência provoca, portanto, a decisão, se ela faltou, e leva à criação de instituições. Patrick $Z y / b e r m a n^{(20)}$ analisa esse processo de decisão, descrevendo invariavelmente "um cenário típico do crescimento administrativo de origem endógena, constituído por um movimento duplo de centralização e de profissionalização do Estado".

\section{Crises inevitáveis}

Enquanto as crises levam a criações institucionais mais ou menos permanentes ${ }^{(21)}$, a prevenção é ineficiente. Os processos modernos de produção e o estreitamento dos laços entre saúde e meio ambiente nas áreas dos riscos difusos ${ }^{(22)}$ fazem com que cada vez mais os poderes públicos tenham de enfrentar novas crises. É necessário, portanto, entender a causa de sua reincidência. Essas causas são evidentemente múltiplas, mas propomos destacar algumas que nos parecem fundamentais.

- A concentração na mãos da mesma autoridade das responsabilidades de avaliação e gestão dos riscos. A avaliação dos riscos baseia-se em dados científicos e na vigilância. As maiores dificuldades de avaliação provêm, de um lado, da insuficiência dos dados disponíveis, e de outro lado, da ausência de perícia que seja suficientemente autônoma e contraditória. A maior parte da fase de avaliação é deixada nas maõs dos cientistas e peritos. Quanto à gestão dos riscos, ela perma-

(19) Lei n. 98-535 de $1^{9}$ de julho de 1998 relativa ao reforço da vigilância sanitária e ao controle de segurança sanitária dos produtos para uso do ser humano. JO de 2 de julho de 1998, pp. 10056 e ss. ou http://www. legifrance.

(20) Patrick Zylberman, Sécurité sanitaire: le retour?, Esprit aouût-sept., 1999, p. 48.

(21) A respeito dos imprevisíveis da longevidade das instituições, cf. Patrick Zylberman, op. cit., p. 49. Apenas para exemplificar, o Ministério de Higiene, criado em 1992, desaparecido desde 1924 por medida de economia. Referir-se igualmente às agências criadas em 1993 e que irão desaparecer com a implantação da Lei de $1^{2}$ de julho de 1998 , cf. infra.

(22) Surgimento da noção de risco de melo ambiente associado aos meios (riscos profissionais) e às poluiçōes (Seveso, Chernobil, usina da Hague...). 
nece com quem decide. Esse último devendo dar soluções, proceder a estudos custo/benefício, escolher uma solução e avaliá-la. Seja na área de medicamentos, ou na ocasião das questões do sangue e do ar poluído, ou ainda da ESB, uma mesma constatação é necessária, as missões herdadas pelas instituições não poderiam terminar em disfuncionamento. O fato de uma mesma pessoa ter a responsabilidade de avaliar os riscos e de gerí-los leva à imobilidade. As carências, comuns ao conjunto das questões, podem então ser destacadas: uma ausência de transparência que leva ao "endeusamento"(23) das informações, uma falta total de sistema de vigilância adequada a revelar em tempo um disfuncionamento e, por fim, uma tomada de decisão bem fraca ${ }^{(24)}$.

Em virtude do art. L. 667-5 do Código de Saúde Pública, a Agência Francesa do Sangue concentra várias competências: ela está incumbida de promover a doação de sangue, de preparar os esquemas que organizam a transfusão sangüinea, de informar o ministro sobre os preços de cessão dos produtos. Segundo o senador Huriet, "tal confusão existe, também, porém em menor escala, nas funções do Estabelecimento francês de transplantes".

Além disso, esse monopólio da decisão está além disso freqüentemente ligado à proeminência dos interesses econômicos que dizem respeito às escolhas que estas autoridades tenham de fazer.

- A confusão dos interesses econômicos e sanitários: é inconcebível que a segurança sanitária possa ser confiada a uma autoridade que tenha como incumbência a função de garantir a boa saúde econômica de um setor. Assim sendo, convém evitar os conflitos entre as duas questões em jogo, procedendo a uma separação funcional entre as responsabilidades de gestão de um setor e as funções de controle ${ }^{(25)}$, ou aquelas que regem os preços.

Vários exemplos dramáticos legitimam essa separação: na questão do sangue contaminado, o importante valor do comércio dos estoques de produtos sangüíneos, a vontade de permitir ao Instituto Pasteur compensar seus atrasos em face da produção americana de testes confiáveis e o custo, julgado exorbitante, da despistagem sistemática retardaram em alguns anos a

(23) A extremamente pouca transparência administrativa que envolveu as questões relativas ao sangue e ao ar contaminados levou a muito mais que uma retenção de informação, a uma verdadejra mistificação, paralelo emprestado à linguagem nuclear "esconderijo em verdadeiros santuários de detritos radioativos, enquanto se aguardava saber o que poderia ser feito com isso.

(24) Na questāa do sangue contaminado, o Estado deu-se conta de sua responsabilidade na omissão culposa (CE, ass. 9 de abril 1993, M.G., M.D. e Mme. B), no exercício de seu poder privilegiado de polícia sanitária. Desta forma, o encarregado do governo Legal levantava o fato que "em 22 de novembro de 1984 no mais tardar, uma administração adquadamente constituida e tendo poder de decisảo quanto os que ela detinha, não poderia de forma alguma retringir-se a permitir que estudos prosseguissem e que as omissōes perdurassem. Nesta ocasião, o risco era suficientemente certo para proibir a inatividade". Sobre a questão da ausência de decisão, ver também Emmanuel Cadeau. Le médicament en droit public - sur le paradigme de l'apothicaire, Thèse pour le doctorat en droit. Nantes, 1997, pp. 270 e ss.

(25) Didier Tabuteau, Les pouvoirs publics et le risque sanitaire, RFAS n. 4-1994, pp. 29 e ss. 
tomada de decisão. Esse atraso foi maior ainda no caso do amianto. A atribuição da perícia e da decisão ao Comitê Permanente do Amianto, Comité Permanent Amiante (CPA), financiado pela Associação francesa de amianto, resultou no atraso flagrante da França na decisão de probir o uso de amianto.

- A fragmentação do processo de decisão e sua falta de coordenação(26): as agências e outros protagonistas implicados na decisão em saúde pública dependem de ministérios diferentes. Desta forma intervêm os Ministérios da Saúde (Direção Geral da Saúde), da Agricultura (fiscais veterinários), da Economia, das Finanças e da Indústria (serviços de controle das fraudes, Órgão de Proteção contra os Raios Ionizantes - Office de Protection contre les Rayonnements lonisants OPRI), do Meio Ambiente (Instituto nacional do meio ambiente industrial e dos riscos - Institut national de l'environement industriel et des risques - INERIS, Instituto da proteçāo e da segurança nuclear, Institut de la protection et de la sûreté nucléaire - IPSN, Agência de meio ambiente e controle da energia, Agence de l'environement et de la maitrise de l'énergie - AEME). A estas autoridades acrescenta-se a participação dos serviços descentralizados competentes.

Uma tal fragmentação das competências torna difícil toda tomada de decisão eficaz e aplicável. O exemplo da legislação relativa à água é significativo: o serviço competente depende da característica das águas em questão (domínio, portos, praias, qualidade da água, gestão da água). A gestão da água é portanto da competência tanto de estabelecimentos públicos (portos e águas dominiais) quanto de administrações descentralizadas ou de ministérios diferentes (Saúde, Meio Ambiente).

Além disso, a falta de coordenação entre esses vários interventores aumenta o disfuncionamento da gestão de riscos. Ora, o Ministério da Saúde, por falta de recursos suficientes, não soube desenvolver um poder de coordenação adaptado a esses participantes. Assim sendo, convém fazer com que a definição e a coordenação da política de segurança sanitária sejam de responsabilidade do Ministério da Saúde. O Conselho Constitucional lembrou que a proteção da saúde faz parte das funções essenciais do Estado. É, portanto, de alçada do Ministério da Saúde elaborar a gestão do risco sanitário.

- A ausência de reconhecimento da noção de alerta: apesar de a idéia de vigilância permanente existir há muito tempo ${ }^{(27)}$ no direito francês, não existe verdadeiro reconhecimento jurídico da vigilância sanitária na França, a prioridade sendo freqüentemente dada a estudos epide-

(26) O esfacelamento dos processos de decisão pode surgir como uma solução à concentração dos poderes supramencionada. Na realidade a atomização horizontal dos "centros" de decisāo entre vários ministérios é um fator de complexidade da decisão.

(27) Existe de fato uma abundância de órgãos públicos ou privados que participam desta missão. $\mathrm{Na}$ realidade, existia desde 1992 a Rede Nacional de Saúde Púlbica. Esta rede tinha pouca eficiência, apesar de o seu orçamento ter dobrado em 1997 e seu efetivo passou a ter de 5 a 35 pessoas entre 1993 e 1997. 
miólogicos específicos. Entretanto, existem soluções. Aquela desenvolvida pela Lei n. 98-535, de $1^{\circ}$ de julho de 1998, passa pela constituição de uma instituição ad hoc (Instituto da Vigilância Sanitária) cuja missão é "detectar qualquer evento imprevisto, anormal, antes que tenha surgido completamente ou tão logo tenha surgido(28)". Em compensação, a proteção do "alertador ${ }^{(29) "}$ é sempre mal garantida. O direito francês só prevê o alerta, no quadro de Código do Trabalho (art. L. 432-5, para direito de alerta do CHSCT e L. 231-8-1 para os deveres de alerta e direitos de aposentadoria dos assalariados). Trata-se, portanto, de uma obrigaçāo que faz parte do contrato de trabalho. Nenhum texto prevê uma obrigação semelhante ou faculdade de dar o alerta por parte de um cidadão no interesse da saúde da coletividade e das gerações futuras. Pior ainda, as ações nesse sentido são sancionadas. Serve de exemplo o licenciamento de um membro do INRS, cujo relatório atacava a avaliação e o controle dos riscos de uso do éter de glycol ou ainda o de um médico do trabalho EDF, por ter levado nos serviços "epidemiólogicos" estudos sobre os cancerígenos profissionais, tais como o amianto, ou sobre as conseqüências de recurso massisso aos maus-tratos quando das intervenções de manutenção das centrais nucleares ${ }^{(30)}$.

\section{A gestāo dos riscos atrapalhada pela sua percepção social}

A percepção dos riscos pelo público pode, em alguns casos, influir na apreensão dos riscos pelos tomadores de decisão.

A tolerância da sociedade quanto aos riscos coletivamente aceitos, como, por exemplo, os riscos ligados aos automóveis ou ao uso do fumo ou do álcool, é extremamente elevada. Da mesma forma, o risco não suscita verdadeira emoção quando se restringe aos locais de trabalho. De fato, ninguém contesta as normas internacionais de radioproteção, uma vez que se baseiam num cálculo que visa a determinar o número de mortos esperado, para que a sobrevida da atividade econômica seja garantida.

Todo o problema de fato reside na análise de custo/benefícios que deve ser conduzida entre as vantagens de uma atividade e seus riscos para a saúde, mas também seus prejuízos socioeconômicos. Esta análise é da alçada do Estado, no quadro de sua missão de elaboração das políticas de gestão dos riscos.

(28) Claude Huriet, Les conditions du renforcement de la veille sanitaire et du contróle de la sécurité sanitaire des produits destinés à l'homme en France. Comission des Affaires Sociales du Sénat, Rapport d'information n. 196, 1996-1997.

(29) M. A Hermitte e Ch. Noiville, L obligation d information en matière sanitaire à la lumière de la loi du 1er. Juillet sur la sécurité sanitaire. Gz. Pal. 23-24 août 1998, pp. 42 e ss.

(30) B. Cassou e M. Schiff, Qui décide de notre santé, le cytoyen face aux experts. Paris: Syros, $1998,263 \mathrm{p}$. 
Ora, no domínio da saúde, a percepção social dos riscos é objeto de um verdadeiro fantasma coletivo ${ }^{(31)}$, alguns riscos tendo sido julgados inaceitáveis pela população, mesmo que a probabilidade do desenvolvimento de doenças ou afecções seja muito mais fraca do que para os riscos ligados ao tabaco e ao álcool. De fato, desde que os elementos vitais externos ao organismo estão em causa (água, ar, alimentos, sangue transfundido), a aceitação do risco é próxima a zero.

A responsabilidade penal das pessoas de direito público tem crescido por causa disso, à medida que os riscos aumentam e se tornam difíceis de avaliar. Convém, portanto, fundar a gestão dos riscos num sistema que permite aos responsáveis coletivos e individuais assentar a segurança sanitária do amanhã.

\section{B - A Vontade de Instaurar um "Sistema de Segurança Sanitária" Coerente}

Se a legislação evolui graças às crises e se as crises permanecem inevitáveis, é inevitável também que o direito progrida e com ele a gestão dos riscos sanitários.

Como prova, o aparecimento da noção de segurança sanitária, por ocasião do debate sobre a reforma da transfusão de sangue. A segurança sanitária estende-se hoje a todos os produtos e a todas as atividades necessárias à preservação da saúde. Ela implica que sejam tomadas medidas que visem a avaliar e prevenir os riscos, como também reduzir seus efeitos caso ocorram. Assim, as obrigações no domínio da saúde para a população aproximam-se das obrigações que pesam sobre os empregadores no que se refere aos riscos profissionais. De fato, desde a Lei n. 91-1414, de 31 de dezembro de 1991, o direito do trabalho é regido por uma obrigação geral de segurança com base nos seguintes princípios gerais de prevenção (art. L. 230-2 do código do trabalho):

- evitar os riscos;

- avaliar os riscos que não podem ser evitados;

- combater os riscos na sua fonte;

- adaptar o trabalho ao homem;

- levar em conta o estado da evolução técnica;

- substituir o que for perigoso pelo que não ofereça riscos ou que seja menos perigoso;

- tomar as medidas de proteção coletiva dando-lhes prioridade sobre as individuais;

- dar as instruções adequadas ao trabalhador.

(31) Cf. Os riscos sanitários e sua influência nas democracias pluralistas: percepçcão, avaliação e gestão. Quais pesquisas desenvolver?, seminário do CNRS no quadro do programa Saúde e Sociedade, Paris, 30 de novembro a $1^{\circ}$ de dezembro de 1998. 
A enumeração destes princípios teria sido mais discreta no quadro das Leis de 1993 e na reforma feita pela Lei de 1998. Esses textos legislativos, entretanto, têm como meta fazer com que a segurança sanitária esteja apoiada em três pilares, e sobre alguns princípios que convém lembrar.

\section{Os três pilares da segurança sanitária}

Uma segurança sanitária coerente apoia-se na organização da gestão de riscos ao redor de três pólos essenciais: a segurança sanitária ligada aos tratamentos, a segurança alimentar e a proteção da saúde contra os efeitos da poluição.

- A segurança sanitária ligada aos trâmentos concerne às políticas de vigilância de doenças transmissíveis, dos sistemas de vigilância, da política dos medicamentos, do controle sanitário nos sistemas de tratamento. A criação de agências é uma idéia amplamente difundida e usada nos países que organizam a segurança sanitária dos produtos de tratamento. A estratégia francesa apóia-se num sistema misto (ver infra (I), que por sua vez se apóia numa gestão dividida entre o Ministério da Saúde e as agências hospitalares.

A vigilância é dividida entre vários órgãos: o Ministério da Saúde gere a vigilância dos materiais, as demais vigilâncias fazem parte das novas atribuiçōes da Agência Francesa de Segurança Sanitária dos Produtos de Saúde, l'Agence Française de Sécurité Sanitaire des Produits de Santé (AFSSPS), que substitui a Agência de Medicamentos para as autorizações de colocação no mercado e para o controle dos produtos, l'Agence du Médicament pour les Autorisations de Mise sur le Marché et le contrôle des produits (AMAMMCP). O controle dos estabelecimentos de saúde é das Agências Regionais de Hospitalização, Agences Régionale d'Hospitalisation $(\mathrm{ARH})$.

- A segurança alimentar é concerne ao controle da produção alimentar, à repressão e controle de fraudes e ao controle dos meios de produção. Inicialmente assegurada pelos serviços do Ministério da Agricultura e da Economia, ela é garantida, desde a Lei de 1998, pela Agência Francesa de Segurança Sanitária dos Alimentos, l'Agence Française de Sécurité Sanitaire des Aliments (AFSSA).

- Quanto à proteção da saúde contra as poluições, último dos três pilares, ela estava dividida, até 1998 , entre os diferentes serviços dos ministérios, que têm como incumbência a vigilância dos ambientes. A deficiência dos meios atribuídos (ex.: quanto ao pessoal, apenas dois agentes são encarregados do escritório de radioproteção no Ministério da Saúde) e a ausência de definição de uma política global fazem dele o pior setor armado da segurança sanitária.

\section{Os princípios da segurança sanitária}

Dois grandes princípios regem a segurança sanitária: o da separação das funções e, agora, o célebre princípio de precaução. 
Segundo o relatório do senador Huriet, um sistema de segurança sanitária coerente apóia-se numa separação das funções de gestão, de controle e da perícia no domínio da saúde.

A gestão deve ser confiada a uma autoridade que goze de verdadeira autonomia de decisão, para que apenas as preocupações sanitárias entrem no jogo, excluindo-se os interesses puramente econômicos. Eis porque a Agência do Medicamento tinha o encargo das autorizações para colocação de produtos no mercado, enquanto o Ministério dirigia a política de preços no Comitê Econômico do Medicamento. Esta autoridade deve-se beneficiar de fontes de recursos suficientes. Com o Ministério da Saúde sendo tradicionalmente mal favorecido, a escolha da agência permite aumentar as fontes de recursos e, sobretudo, beneficiar-se de receitas próprias quando não é possível afetar receitas do orçamento do Estado, em razão do princípio da universalidade orçamentária (não afetar). Assim, os arts. L. $792-7$ e 793-9 prevêm nos recuros do IVS e do ASSPS o produto dos pagamentos por serviços prestados ou das subvenções dos organismos de seguro social.

O controle deve ser feito por setores especializados, com poder de polícia, sejam eles de poder de polícia administrativa clássica (declaração obrigatória, autorização e apreensão) ou por medidas de polícia específica na área sanitária ("levar a bom termo todas as ações necessárias para identificar as causas para uma modificação do estado da saúde da população, principalmente em casos emergenciais ${ }^{(32) ")}$.

Enfim, a perícia deve atender aos principios da independência dos peritos, à transparência e ao caráter contraditório da perícia. Entretanto, o relatório da Agência do Medicamento, em 1995, revelava que dois terços dos membros das comissões ligadas a essa agência declaram ter interesses numa ou várias indústrias farmacêuticas (contratos de trabaiho, cotas de participação, trabalhos desempenhados contra-remuneração ou outros interesses declarados). A vitória foi de um membro da comissão de autorização para colocação no mercado de medicamento, que declarou 45 interesses diferentes.

Segundo principio que, de agora em diante, deve guiar as decisões na área da saúde pública é o princípio de precaução. A consagração jurídica do princípio de precaução é um elemento essencial de coerência. Obrigando os agentes a refletir quanto ao risco, a aplicação do princípio de precaução exige ultrapassar as simples medidas de prevenção contra os riscos conhecidos. Em relação aos novos riscos, ligados a exposições de doses fracas, convém agir ainda quando a prova científica faça falta ou que seja insuficiente para afirmar a existência ou ausência de risco. Embora o princípio de precaução tenha passado por várias formulações desde a Conferência do

(32) Art. L. $792-1, \S 3^{\circ}$, do Código de Saúde Pública - missōes e prerrogativas do Instituto da Vigilância Sanitária. 
Rio, em 1992, convém não fazer dele um princípio de abstenção. Os poderes públicos devem intervir mesmo que seja para impôr uma moratória, o que os cientistas consideram uma forma de atraso na pesquisa.

\section{O SURGIMENTO DAS AGÊNCIAS NO MUNDO ORGANIZACIONAL FRANCÊS}

Uma vez postos os princípios que regem o processo de decisão e de renovação da gestão de saúde da população, convém apresentar a natureza e o conteúdo da resposta francesa à falta de coerência de seu sistema de segurança sanitária. Num primeiro momento, uma análise do "modelo francês" da agência será empreendida (A) para depois dar mais atenção aos desafios da Lei de 1998 e suas realizações (B).

A - O modelo francês de segurança sanitária: a conciliação entre uma intervenção ministerial e a criação de agências

Levando em conta as lições tiradas das experiências obtidas durante uma década e, principalmente, desde a criação da Rede Nacional de Saúde Pública, Réseau National de Santé Publique (RNSP) (1992), da Agência dos Medicamentos (1993), da Agência Francesa do Sangue (1993), do Estabelecimento Françês de Transplantes (1994) e da Agência Nacional de Acredição e Avaliação em saúde, Agence Nationale d'Accréditation et d'Evaluation en santé (ANAES) (1996), várias possibilidades se apresentaram aos poderes públicos franceses e principalmente aos parlamentares que estāo na origem das mudanças efetuadas.

A volta de uma gestão ministerial parecia inconcebível, na medida em que o legislador reconhecia os efeitos positivos das agências criadas anteriormente e que funcionavam até então, tal como a Agência dos Medicamentos.

Restava a alternativa de "toda agência" ou da divisão de competências entre as agências e uma autoridade de tutela.

Qualquer que seja o termo usado para a alternativa escolhida, implicará a persistência de uma "lógica de agência(33)".

Desde já é necessário precisar que, no direito francês, as agências não constituem uma categoria jurídica específica. Jacques Chevallier diz que "a agência seria caracterizada por três traços essenciais: a qualidade da pessoa pública distinta do Estado; a aplicação de uma política setorial nacional; a ação exercida por conta do Estado, em virtude de uma transferên-

(33) Ver Emmanuel Cadeau, cit., p. 276. 
cia explícita das competências ${ }^{(34) " . ~ E s s e ~ a u t o r ~ a c r e s c e n t a ~ a i n d a ~ q u e ~ a ~ f o ́ r m u-~}$ la implica recorrer à forma jurídica do estabelecimento público administrativo, preferivelmente aos estabelecimentos públicos industriais e comerciais e aos grupos de interesse público. De fato, as agências francesas têm, em maior parte, o estatuto jurídico da EPA ${ }^{(35)}$, e essa escolha não é inofensiva: ela permite a identificação rápida dos responsáveis. A crise da vaca louca colocou em destaque a impossibilidade de identificar com clareza os responsáveis pelas decisões em uma organização ministerial esfacelada e complexa. Num sistema de estabelecimentos públicos, os responsáveis são facilmente identificáveis, mesmo se o Ministro da Saúde continua sendo o "responsável" pela política de saúde pública.

\section{O "terceiro caminho francês"}

O movimento de criação de estabelecimentos públicos independentes do poder político é percebido com referência ao modelo organizacional dos Estados Unidos. O modelo americano supõe uma retirada da administração do Estado. Estruturados em agências (os Centros para Controle de Doenças e Prevenção no que diz respeito à vigilância, a Agência de Proteção ao Meio Ambiente para os riscos de meio ambiente e a Administração de Medicamentos e Alimentos para o controle dos medicamentos, dos produtos de saúde e dos alimentos que não incluem carne de boi e ovos), os agentes da gestão dos riscos sanitários só devem satisfações de suas atividades ao próprio Congresso.

Na Grã Bretanha, o recurso à criação de agências é baseado na idéia da eficácia das políticas públicas. Trata-se de colocar as agências ao abrigo das pressões políticas para garantir sua rentabilidade ${ }^{(36)}$.

Em suma, nos países anglo-saxões está excluida toda e qualquer intervenção do poder executivo.

Os parlamentares franceses escolheram uma terceira via que está situada entre a gestão puramente ministerial (que falhou) e esse modelo de "tudo agência". A via francesa implica sempre a criação de agências (pessoas morais de direito público, juridicamente distintas do Estado, sob uma tutela ministerial, ou mesmo interministerial) e uma coordenação do Estado entre as diferentes agências, por um lado, e as agências e serviços descentralizados, por outro lado, atuando por intermédio de seus representantes na hierarquia local que são os prefeitos.

(34) Jacques Chevallier, Les agences: effets de mode ou révolution administrative?, p. 55.

(35) Elas podem tomar a forma jurídica de um Grupo de Interesse Público (ex.: Rede Nacional de Saúde Pública).

(36) Cf: intervenção de Jacques Chevallier, "Apresentaçāo teórica do modelo da agência", in Les agences dans le domaine de la santé - approches comparées, 17ème. Nantes, Atelier du CERDES, 26 a 27 de março ce 1999. 
Estes elementos constituem o "tronco comum" do modelo francês. Além disso, a agência parece ser uma "nebulosa":

- em primeiro lugar, há a possibilidade de as competências serem exercidas não em nome da agência, mas do Estado. Por exemplo, no que diz respeito à AFSSPS, o art. L. 793-4 do Código de Saúde Pública diz que "o diretor geral da Agência do Medicamento toma em nome do Estado as decisões que resultam da competência da Agência".

- em segundo lugar, a autonomia dada às agências não significa que elas escapem a todo controle administrativo. Assim, retomando o mesmo exemplo, se o mesmo art. L. 793-4 diz que as decisões do diretor da Agência não são suscetiveis de ser objeto de um recurso hierárqui$c o$, apenas indica que o Ministro da Sáude pode pedir uma segunda deliberação, em caso de ameaça grave para a saúde pública. Seria útil definir os elementos que constituiriam um "caso de ameaça grave para a saúde pública".

Em contra partida, em virtude do art. L. 794-3 do Código de Saúde Pública relativo à AFSSA, o legislador é mudo quanto à faculdade dada ao ministro de se opor às decisões do seu diretor.

- e por último, todas as agências nascidas da Lei de 1998 não foram investidas das mesmas missões: por exemplo, só a AFSSPS detém os poderes de polícia e possui um corpo de inspetores especializados; apenas a AFSSPS e a AFSSA participam na elaboração das regulamentações e só a EFS garante a gestão dos produtos que fazem parte do seu campo de competência.

A apresentação das agências instauradas pela Lei de $1^{9}$ de julho de 1998 irá ainda ilustrar esta diversidade, depois da exposição do objeto da nova intervenção do legislador.

\section{B - Um apanhado da Lei n. 98-535 de 1 de julho de 1998}

O reforço da segurança sanitária revela-se necessário

A crise da vaca louca permitiu ressurgir os disfuncionamentos da segurança sanitária francesa, cujas bases foram extraídas da criação das agências a partir do "modelo" de 1993. Convém, portanto, entender as razões de tal disfuncionamento. Reside ali o objetivo principal revelado pelo relatório da missão de informação da Comissão dos Assuntos Sociais da Assembléia Nacional(37).

Esse relatório colocou em evidência dois vetores de disfuncionamento: a insuficiência dos meios de vigilância sanitária e das regras que garan-

(37) Relatório Huriet, cit. 
tem a segurança sanitária; e a diversidade e a fraqueza da coordenação das estruturas encarregadas das questões de segurança sanitária.

O relatório fala também das falhas próprias de cada um dos pilares da segurança sanitária, queixas que, para a maioria deles, podem ser generalizadas em todo o sistema.

No que se refere ao segmento tratamentos e produtos de saúde, a gestão dos riscos parece bastante coerente graças à experiência até então adquirida nessa área pelas diversas agências. Mas o tratamento setorial introduzido pela constituição de agências traz inevitavelmente falhas na gestão dos produtos. Assim o relatório Huriet enumera um certo número de produtos sem existência jurídica: as substâncias e preparações utilizadas na assistência médica à procriação, as plantas medicinais, os produtos dietéticos e os complexos nutricionais, as lentes de contato coloridas, os protetores solares, os "xeno-implantes" de órgãos ou de células.

Quanto às condições de segurança alimentar, ainda não estão reunidas. Nenhuma avaliação estatística exaustiva dos males e doenças alimentares está prevista. Além disso, os controles sobre a segurança alimentar são insuficientes e a independência dos fiscais em relação aos produtores não está garantida.

Quanto ao princípio de precaução, que deveria ter um papel essencial na área da segurança alimentar, é pouco ou quase nada aplicado. É claramente o caso da questão da resistência aos antibióticos (a questão da avoparcina e OGM).

No que diz respeito à vigilância sanitária, enfim o relatório destaca a falta de recursos, o caráter pouco eficaz e a ausência de coordenadção dos diversos órgãos públicos ou privados incumbidos da vigilância sanitária. A condução de uma política coerente de saúde pública passa, entretanto, pela detecção das ocorências suficientemente cedo para que as decisões possam ser tomadas. Esta necessidade é, aliás, uma condição primordial para a aplicação do principio de precaução, sendo hoje essencial separar as atividades e os produtos que não contêm nenhum risco no momento de sua concepão, e aqueles para os quais um início de questionamento introduz a dúvida, depois uma incerteza científica, dando lugar ao princípio.

\section{As criações da Lei de 1998}

Relembremos, para começar, que o nome agência não é uma inovação da Lei de $1^{\circ}$ de julho de 1998, uma vez que as primeiras agências francesas na área de saúde foram criadas em 1988 (Agência Nacional de Pesquisa da AIDS, Agence Nationale de Recherche sur le SIDA e Agência Francesa de Luta contra a AIDS, Agence Française de lutte contre le SIDA), em 1989 (Agência Nacional para o Desenvolvimento da Avaliação Médica, Agence Nationale pour le Développement de l'Évaluation Médicale - ANDEM) e em 1990 a ADEME. 
As Leis de 4 de janeiro de 1993 e de 18 de janeiro de 1994 confirmaram a entrada da segurança sanitária na "era da agência". Nessa ocasião, foram de fato criadas a Agência do Medicamento, a Agência Francesa do Sangue, o Estabelecimento Francês de Transplantes e o Escritório de Proteção contra os Raios lonizantes. Posteriormente, houve outra onda de criação de agências, cujo objetivo era reforçar a coerência do sistema de segurança sanitária.

Com a Lei de $1998^{(38)}$, várias instituições nasceram, algumas sendo criações novas, outras a reestruturação de instituições já existentes ${ }^{(39)}$. Em vista do aumento crescente das situações de crise na Europa e particularmente na França, tornou-se essencial repensar a organização administrativa com o fim de reforçar a segurança sanitária.

Estas novas instituições são:

O Comitê Nacional de Segurança, Comité National de Sécurité (CNS): o art. L. 796-1 do Código de Saúde Pública prevê a criação de um comitê cuja vocação interministerial é limitada (o Ministro da Saúde agrega às suas tarefas os ministros, garantindo a tutela de uma agência, ou então pode associar "qualquer outra pessoa ou organismo competente").

Esse comitê analisa e compara as informações relativas aos acontecimentos suscetíveis de prejuizos à saúde. Ele exerce também uma missão de coordenação das políticas científicas das agências.

O Instituto de Vigilância Sanitária, Institut de Veille Sanitaire (IVS): (art. L. 792-1 do Código de Saúde Pública). Estabelecimento Público Administrativo, Etablissement Public Afministratif (EPA), seu campo de ação cresce do conjunto dos riscos sanitários. O IVS está sob a tutela do ministro encarregado da saúde. Suas missões são:

- realizar a vigilância e observação permanete do estado de saúde da população tendo como apoio os agentes públicos e privados;

- alertar os poderes públicos das ameaças contra a saúde pública;

- emitir recomendações às duas agências (AFSSPAS e AFSSA) quanto às medidas de ações a serem empreendidas.

Esse estabelecimento não tem poder normativo, não dispõe de poder de polícia. O IVS contribui para separar e centralizar a vigilância sanitária, que até então era subdividida e colocada nas mãos de várias instituições: Rede SENTINELLE, INSERM e RNSP.

A Agência Francesa de Segurança Sanitária dos Produtos de Saúde, Agence Française de Sécurité Sanitaire des Produits de Santé (AFSSPS):

(38) E seus decretos de aplicação, sendo que o primeiro é de 4 de março de 1999, JO de 5 de março de 1999.

(39) Agência Francesa do Sangue e Estabelecimento Francês dos Implantes. 
trata-se de um EPA sob a autoridade do ministro responsável pela saúde. Sua funções são as seguintes:

- ela retoma as competências e as tarefas da antiga Agência do Medicamento que desapareceu. Ela abrange também as competências do AFS; a administração e a distribuição dos produtos derivados do sangue são confiadas a um novo Estabelecimento Francês do Sangue ${ }^{(40)}$;

- ela exerce o conjunto de funções, da regulamentação à perícia, passando pela detenção dos poderes de polícia sanitária.

Para realizar essas funções, a AFSSPS faz ou manda fazer toda a perícia ou controle técnico, recolhe os dados no domínio de sua competência (farmaco vigilância), toma todas as medidas de proteção da saúde pública, participa na aplicação das regras do mercado no que diz respeito aos produtos sanitários e cosméticos e dispõe de um corpo de fiscais que tem como missão controlar a aplicação das regras relativas aos produtos sanitários e cosméticos. A agência pode suspender ou interditar atividades em caso de grave perigo para a saúde do ser humano.

A Agência Francesa de Segurança Sanitária dos Alimentos, Agence Française de Sécurité Sanitaire des Aliments (AFSSA): Seu campo de ação encampa o conjunto dos mecanismos de produção da cadeia alimentar, incluindo os aspectos veterinários e fitosanitários. Assim, a AFSSA está colocada sob a tutela dos Ministros de Saúde, da Agricultura e do Consumo. Na agência, é prevista a separação das funções de perícia científica e de gestão dos riscos: seus poderes de polícia são limitados (a Agência pode apenas pedir aos ministros em questão que mandem fazer os controles ou investigaçōes necessárias pelos agentes habilitados). Ela se limita, portanto, principalmente nas missões de perícia e de conselhos, a não constituir, portanto, o equivalente à Agência de Segurança Sanitária dos Produtos de Saúde. Note-se, igualmente, o fato dela gerir o Centro Nacional de Estudos Veterinários e Alimentícios, Centre National d'Études Vétérinaires et Alimentaires (CNEVA) que lhe está diretamente ligado. No CNEVA, a Agência Nacional do Medicamento Veterinário, l'Agence Nationale du Médicament Vétérinaire (ANMV), dá autorizações para colocar no mercado medicamentos veterinários.

De forma geral, as condiçōes de uma perícia transparente e contraditória são reforçadas pela:

- criação de conselhos científicos ${ }^{(41)}$ encarregados de vigiar a "coerência da política científica" das agências;

(40) Os centros de transfusão de sangue são nacionalizados e constituem, portanto, as antenas locais da EFS.

(41) Arts. L. 793-3 para a AFSSPS, L. 794-3 para a AFSSA e art. 4 da seção 2 da proposta da lei relativa à criação da Agẽncia Francesa de Segurança Sanitária e do Meio Ambiente. 
- a faculdade de recorrer, nos casos de CDD ou de CDI, aos contratos de direito público. Essa liberdade permite aos agentes usar, pontualmente ou não, personalidades científicas distintas dos pesquisadores, engenheiros e pessoal técnico das agências: uma perícia pluridisciplinar e contraditória é, a priori, tornada possivel.

O título IV da Lei de 1998 refere-se ao último setor da segurança sanitária: a proteção contra a poluição e os ambientes. É prevista a criação de uma Agência de Segurança Sanitária do Meio Ambiente, Agence de Sécurité Sanitaire de l'Environement (ASSE). O art. 13 da Lei posterga o debate: "nos seis meses seguintes à promulgação da presente lei, o Governo remeterá ao Parlamento um relatório sobre a oportunidade e a viabilidade da criação de uma Agência de Segurança Sanitária e Ambiental(42)". Em maio de 1998, o Primeiro Ministro incumbe dois deputados de responder a essa exigência. A Sra. Grzegrulka e Sr. Aschieri entregam um relatório em novembro de 1998. As propostas do relatório visam a "reforçar o conhecimento dos riscos, coordenar melhor as intervenções do Estado e seus parceiros e organizar o exercicio da democracia cidadã". Eles pregam, notadamente, a instalação de um Comitê de Ligação Interministerial de Segurança Sanitária Ambiental, Comité de Liaison Interministérielle de Sécurité Sanitaire Environnementale (CLISSE), para formalizar a coordenação interministerial, a criação do Instituto de Vigilância do Meio Ambiente, Institut de Veille Environnementale (IVE), encarregado de juntar, sob a orientação do ministro do meio ambiente, os resultados dos atores da vigilância na área do meio ambiente ${ }^{(43)}$ e a criação de uma Agência de Segurança Sanitária Ambiental. O campo de ação desta agência estende-se à gestão dos riscos ao meio ambiente "doméstico e profissional".

Na primavera de 1999, os deputados apresentaram uma proposiçāo de lei que ainda não foi objeto de debate. Não há dúvida que várias questões serão levantadas por ocasião do exame desta proposta quando inscrita na ordem do dia. Por exemplo, o art. 2 da proposta, que define as funções e as prerrogativas do Instituto de Vigilância Ambiental, dispõe que o instituto "pode ter acesso, atendendo à sua solicitação, às informaçōes protegidas pelo segredo médico ou industrial em condições que preservem a confidencialidade dos dados perante terceiros, de acordo com a definição do Conselho de Estado ${ }^{(44) "}$. Mas, no domínio específico dos riscos profissionais, mesmo se algumas precauções têm desde já sido levantadas, não há dúvidas de que essa faculdade necessita do acordo dos agentes em questāo. O levantamento do sagrado segredo profissional, com a condição de que seja juridicamente enquadrado, parece ser, entretanto, um meio eficaz de remediar a declaração das doenças profissionais e dos acidentes de trabalho, fenôme-

(42) Cf. art. 13 da Lei n. 98-535.

(43) Instituto Francês do Meio Ambiente (IFEN), ADEME, redes de vigilância da qualidade do ar, Escritório da Pesquisa Geológica e das Minas, Museu da História Natural, IFREMER, Escritório Internacional da Água, INERIS.

(44) A IVS já dispōe desta liberdade. 
no que não permite "efetuar a vigilância e a observação permanente do estado do meio ambiente" com o objetivo de "juntar e atualizar os conhecimentos científicos, técnicos e tecnológicos sobre os riscos ao meio ambiente, suas causas e sua evolução(45)".

Definitivamente, a Lei de 1998 e seus decretos de aplicação, bem como a continuidade da lei pela proposta mencionada, definem o quadro de um sistema de segurança sanitária mais coerente sobre a prevenção e a gestão por "setores ${ }^{(46) "}$ que por produtos.

Entretanto, convém que o Estado elabore, em conjunto com seus parceiros europeus e dentro do quadro de engajamento plurianual, uma verdadeira política de segurança sanitária. Da mesma forma, deverá ser criado um espaço para a participação do cidadão e para a comunicação das informações ao público. Entretanto, a Lei de 1998 não prevê a obrigatoriedade de comunicação da informação por parte daquele que a detém (somente as agências podem pedir a comunicação de informações necessárias ao exercício de suas tarefas). Por outro lado, se uma obrigatoriedade de informação ao público pesa sobre as agências, ela é "pouco organizada, principalmente no que se refere à alimentação. Ela é estabelecida em determinados momentos previstos por lei, os usuários não estão presentes nas instituiçōes e o contéudo mínimo de informaçōes não está definido(47)".

Espera-se que os futuros debates sobre o reforço de segurança sanitária, visando a ampliá-la para o campo de meio ambiente, saibam, à luz da experiência adquirida nesta área pelo direito do meio ambiente, redefinir o lugar do cidadão nas políticas de saúde pública.

\section{(45) Art. 2.}

(46) A separação da gestão dos produtos de saúde e dos produtos alimentares justifica-se pelos "problemas respectivos (...) extremamente diferentes. Para os primeiros, trata-se de ter segurança de sua eficácia do ponto de vista patológico (...) Para os outros, o risco sanitário é mais ligado às condiçōes de produção das matérias primas agricolas". In, Jacques Bonneau, Examen critique de la loi du 1er. Juillet 1998, relative à veille sanitaire, Gaz. Pal. $23 / 24$ outubro de 1998 , p. 373. Ela constitui, pelo menos, um obstáculo à aproximação global dos riscos para o homem.

(47) M. A. Hermitte e C. H. Noiville, L'obligation d'information en matière sanitaire à la lumière de la loi du 1er. Juiller 1998 sur la sécurité sanitaire, Gaz. Pal. 23/24 agosto de 1998, p. 44. 